\title{
The Identify of Arab Architecture between Originality and Modernity
}

\author{
Dr. Salma Dwidar and Dr. Akram Zayan
}

\begin{abstract}
The traditional architecture of the Arab region presented architectural ideas that had a great role in achieving compatibility with the extreme weather conditions. This architecture was spontaneous without prior attachment to certain architectural considerations. It expressed the role and the prevailing natural, cultural and social environments and was a true reflection of the environmental conditions of the societies in which they originated, in all their natural and social dimensions.

This Arab architectural heritage, which expresses our personality and our environment, was replaced by Western architecture. This does not deny the existence of attempts to respect the cultural environment and the heritage singularities, searching for the Arabian identity and personality. However, so far these attempts are not many and are still trying to reach a satisfactory formula.
\end{abstract}

Keywords - Heritage, Arab Identity, Contemporary, Gulf architecture, Industrial Revolution.

\section{INTRODUCTION}

Since the dawn of history, the main goal of man was to adapt to a good environment, as his physical composition does not help him to change and adapt automatically like other organisms. Therefore, he lived in mountains caves and huts built in primitive ways during prehistoric times to protect him against predators and to overcome climatic fluctuations, as an attempt to create a suitable limited environment. Throughout the ages and civilizations man understood the phenomena of the environment and its geographical and climatic characteristics. Using his intelligence and creativity man was able to develop his home by understanding the various construction methods and figuring out how to take advantage of the surrounding building materials. Over time, man has evolved in choosing his home which suits his needs and is in line with his culture. So, the different buildings everywhere throughout the ages reflect the culture of their peoples and express their civilizations and cultures.

Never once did the Arabs live on the margins of history without having a constructive influence on it. The Arabs were the owners of an immortal message and the builders of one of the greatest civilizations of the Middle Ages.

Dr. Salma Dwidar, Associate professor, Architectural Engineering Department ,Prince Sultan university, KSA

Associate professor, Architecture Department, Faculty of Fine Art , Alexandria University, RAE.

Dr. Akram Zayan Assistant professor, Architecture Department, Faculty of Fine Art, Alexandria University, RAE
Today the Arabs are confused, some of them stand in a crossroad between sorrow over lost glory, and doubt about the past, the present and the future. Some are fascinated by the civilization of the West, unaware of its purpose and goals, unaware that this culture is for a society with its specific and inherited traditions.

contemporary architecture, with its innovative formations and dazzling configurations, is often responsive to cultural aspirations and urgent economic requirements. With the passage of time, it will become different from the architecture of the future, which holds more exciting technological transformations. the architecture of the future continues to reject the buildings of the present. Over time, the patterns and shapes are mixed, which may not happen if heritage is the source of inspiration. So, let us give this heritage a chance for living and evolving. If it proves to be invaluable and unable to evolve and keep pace with time, then we drop it out of mind based on consciousness and remove the confusion that prevails in Arab architecture design concepts.

\section{RESEARCH PROBLEM}

The disappearance of the Arab architectural heritage, which expresses our personality and our environment and replacing it with Western architecture. This does not negate the existence of architectural attempts that seek to respect the cultural environment and the heritage vocabulary, and search for identity and the Arab personality. However, these attempts have not yet reached a satisfactory formula.

\section{A. Goal of research}

- The human demand is to obtain a building that achieves human needs and comfort. This will only happen if the architecture is compatible with the place where the person lives.

- Paying attention to Arab architecture and to the past, to guide the present and the future.

- Narrating the story of the Arab civilization in its entirety, especially after the emergence of great material wealth that threatens Arab civilization with inputs that have no purpose and no value.

- This research aims at reaching a consensus of architectural work, related to Arab culture, civilization and social values. The cultural heritage expressed by the outcome of the figurative and structural principles produced by the skills and experiences and creations produced by society throughout its history. 


\section{B. Research Methodology}

The research methodology is descriptive and analytical, by which we can identify the relationship between heritage architecture and modern technology, concluding results of the analytical study in a theoretical and practical framework that can be applied.

\section{FACTORS AFFECTING THE FORMATION Of THE ARABIAN ARCHITECTURAL IDENTITY}

The architectural and civilized style is affected by the surrounding environment in terms of climatic, social, cultural and economic conditions [1] , as illustrated in Fig. 1.

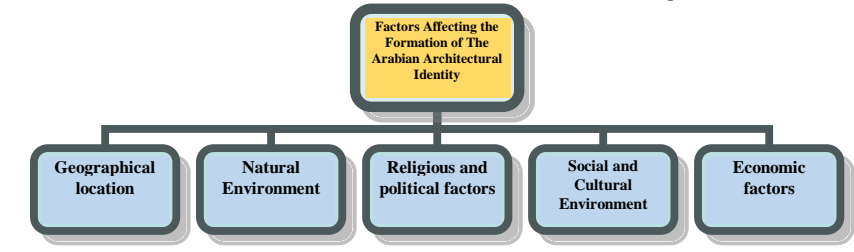

Fig. 1. Factors Affecting the Formation of The Arabian Architectural Identity

\section{GEOGRAPHICAL LOCATION}

The Arab countries extend in the area between the shores of the Arabian Gulf in the east and the shores of the Atlantic Ocean in the west between the latitudes 10,35 north and are bordered by the shores of the Mediterranean Sea in the north.

\section{A. Impact of location on the shape of the external space}

This harsh desert atmosphere helped to create the first architectural base that characterized Arab architecture, namely, organic and environmental conflicts. This affected architectural treatments and the general form of Arabian architecture.

\section{B. Impact of location on city structure}

When it came to planning, the residential communities consisted of a group of residential units with a central courtyard grouped together in an interlocking organic fabric with alleys confined between them, along with pathways for movement which were winding and narrow and surrounded by walls. The walls were semi-solid and gave shade which let them work as a thermal regulator for residential buildings and the city as a whole [2] as shown in Fig.2

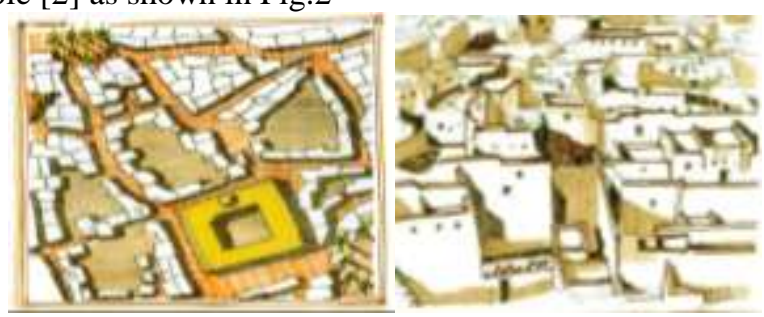

Fig. 2. The Arab city is free of open spaces and proximity of buildings to climate protection and for defensive and social reasons

Fig. 3. Harmonic organic tissue and arched alleys in the city of Ghadames

\section{Impact of location on Urban vacancy}

The desert environment helped to direct human life to the interior. As for the urban vacancy, the vacancy was organic and automatic, free of large urban open spaces, and following the integrated solution in assembling the buildings [3].

\section{Impact of location on Streets and lanes}

The hot climate helped the cohesion of the buildings with one another and continuous walls were built on the sides of the streets and thus more clearly defined the internal urban space of the old city [4]

\section{E. Impact of location on the shape of the buildings}

We always see leniency towards horizontality which is not interrupted except by the verticality of the minarets of the mosques from time to time[5], as shown in Fig. 3, 4 and 5.

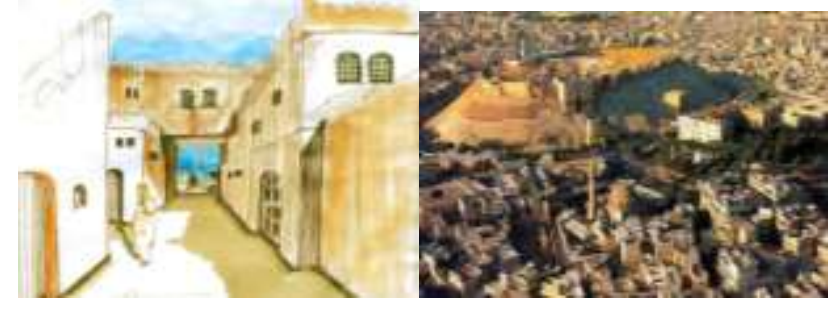

Fig. 4. Impact of climate on life and movement in the Arab streets Fig. 5. architecture characterized by simple form, continuity of mass and the tendency towards the horizontal, which is interrupted only by the minarets

\section{F. Impact of location on building facades}

This focus on the expansion of the space and not identifying it, made the facades occupy a secondary place in the architectural processing. They are characterized by simplicity in the longitudinal configuration of the openings, but rich from the inside with brilliant geometric inscriptions [6].

\section{G. Impact of location on the shape of the interior of the dwelling}

The courtyard is considered one of the architectural elements that dealt with the problems of the environment with great success as it acts as a regulator of the temperature inside the building day and night, through the distribution of thermal load inside the building, as shown on Fig. 7 and 8 .

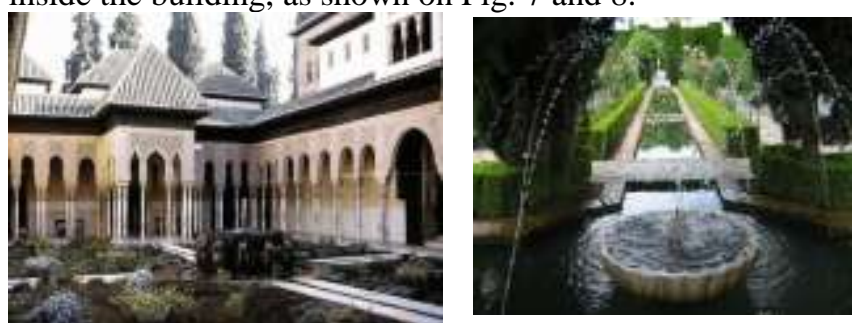

Fig.7,8. Alhambra Palace in Granada: the traffic routes and the treatments they used for protection against the harsh climate

\section{NATURAL ENVIRONMENT}

Includes all non-man-made physical phenomena such as geographical environment and surrounding natural and climatic conditions [7] the natural environment is divided into climatic factors and the nature of the earth as shown in Fig.9. 


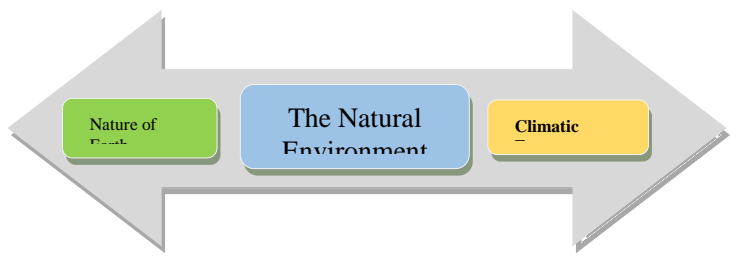

Fig.9. components of natural environment

\section{A. Reflections of climatic factors on architecture}

This is reflected in: Using building materials that are suitable climatically -Using open and closed treatments in architectural design such as yards and air intakes -Treatment of openings naturally or artificially, as shown in Fig. 10.

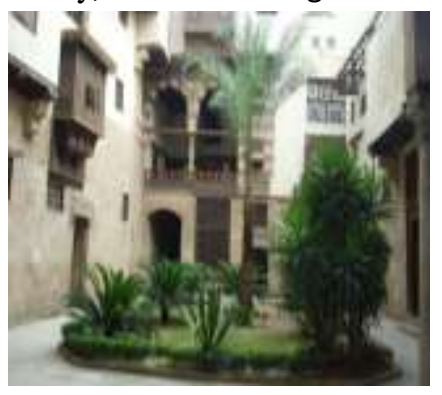

Fig. 10. The effects of climatic factors in architectural design and the use of indoor yards and mashrabiya (House of Sehemi) Cairo

\section{B. Reflections of climatic factors on urban planning}

This is reflected in: Arrangement of buildings and urban groups varies from free form to closed order - Routing of road networks - Height of buildings - Buildings density [8].

\section{Nature of the Land}

The nature of the land on which the city grows; or when choosing the locations of the cities, differs from green plains to desert plains, from barren to green highlands, and from cultivable to uncultivable areas.

\section{Reflections of the nature of the land on the planning of the city}

This is reflected in: Choosing the layout structure of the city Distribution of city elements - Type of the city (industrial touristic - residential - administrative) - Road networks that follow the earth's terrain, as shown in Fig.11.

\section{E. Reflections of the Earth's Nature on Architecture}

This is reflected in: Selection of suitable local building materials, direction of openings in buildings - Construction system - Height of buildings, as shown in fig. 12.
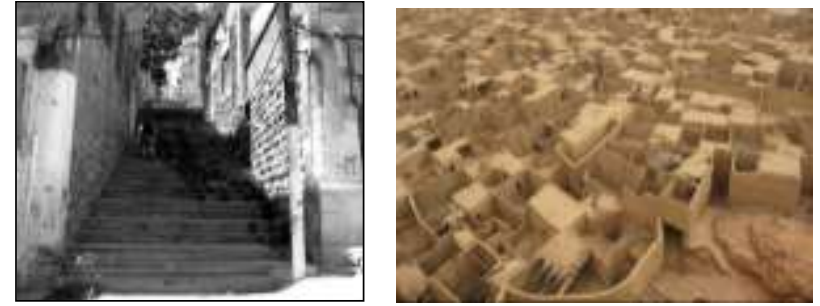

Fig. 11. The effects of the nature of the mountainous land on the street planning in Amman (Jabal Amman Kharfan Street).

Fig.12. Reflection of the nature of the land on the building in terms of heights and openness to the interior.

\section{Religious AND Political Factors}

The Arab city was based on other former cities and expressed itself under the banner of succession, by the Arabic tongue and the new thought resulting from the Islamic call. The Arab man was able to mix all these civilizations and melt them in his crucible to bring the world a new civilization represented in the Arab Islamic city.

\section{SOCIAL AND CULTURAL ENVIRONMENT}

In the urban fabric of the Arab city, the homes of the rich and the poor have been linked to the neighborhood unit without social or class differentiation. The difference between them was achieved through different sizes of houses, their areas and the number of their villas, which affected the diversity of the spatial organization. Equality among members of society is one of the goals of social sustainability. The concept of the neighborhood is one of the most important concepts on which the planning of the Arab city was based, as illustrated in Fig. 13.



Fig.13. The neighborhood unit in accordance with the concept of social sustainability in the urban fabric in the Arab city. In the middle, the movement is blocked at the end to prevent the entry of strangers and maintain the unity of the neighborhood in the Arab city. On the right, the spatial configuration of the inner spaces and their relation to the overall urban fabric of environmental recruitment.

\section{ECONOMIC FACTORS}

Most of the inhabitants of the Arab cities worked in commerce and this was reflected on the Arab street where commercial streets and markets became the most important elements that were associated with the Arab people. The Arab community then relied on sniping and grazing sheep, as illustrated in fig. 14 and 15. 

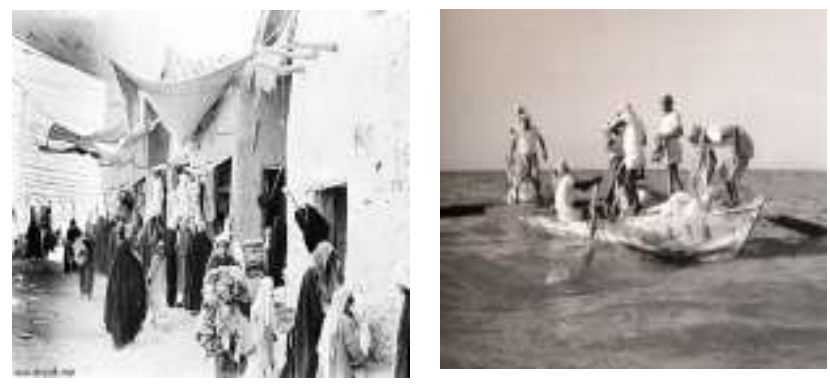

Fig. 14. The southern market of the palace of government in $1371 \mathrm{AH}$, where the community was living signs of commercial openness.

Fig. 15. The Arab community's reliance on fishing.

\section{The Establishment OF InDUSTRIAL REVOLUTION AND THE DISCOVERY OF PETROLEUM}

The scientific revolution and the industrial revolution cannot be separated. Man knew industry when he made primitive weapons to hunt animals and to defend himself. The first shift occurred when the wheel was made, which is the basis of movement. The second shift came when man discovered the steam energy and then the third huge move occurred when he discovered the electrical energy that helped to exploit the forces of nature and its resources, especially oil, which man discovered its origins in the early twentieth century.

\section{A. The Impact of Industrial and Scientific Revolution in Shaping Modern Gulf Architecture}

Electricity, petroleum and its derivatives have cooperated in reducing the world and reducing its dimensions, thanks to the means of rapid transmission and means of communication that were manufactured during the 21 st century, as illustrated in Fig.16.

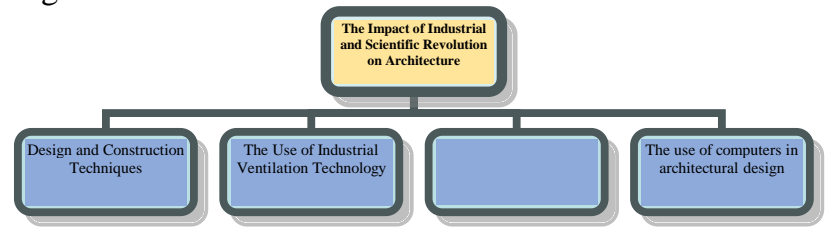

Fig. 16. The Impact of Industrial and Scientific Revolution on Architecture

\section{B. Design and Construction Techniques}

Modern technology has provided many different building materials such as reinforced concrete, glass wool, gypsum and others, and new building methods such as prefabricated units and processing and modern types of glass and plastic. These modern materials have a great impact on contemporary buildings as shown in Fig. 17.

\section{The Use of Industrial Ventilation Technology}

Air conditioning has allowed architects great freedom to make multiple configurations of horizontal projections that were not previously known, for various types of buildings such as hospitals, hotels, conference rooms and covered playgrounds. With modern types of insulation and glass with different specifications and colors, significant degrees are achieved in the elimination of glare and the penetration of the heat of the sun, as shown in Fig. 18.
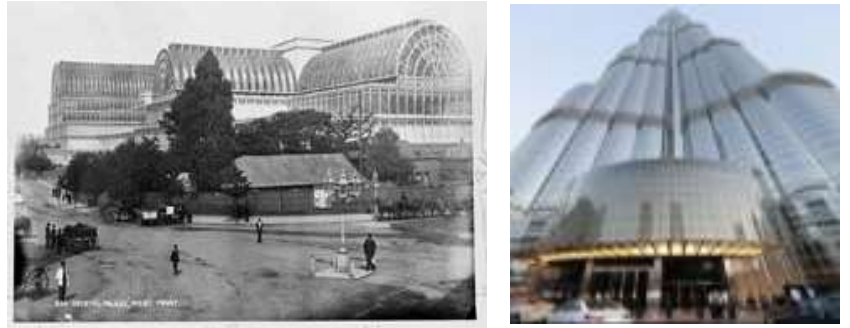

Fig. 17. The Crystal Palace, designed by Sir Joseph Paxton.

Fig. 18. Khalifa Tower in Dubai Means of modern industrial technology (industrial ventilation) helped in the emergence of architectural formations that were not previously known

\section{Means of mechanical transport within buildings}

A-The means of vertical transmission: This type of skyscrapers would not have been possible without the availability of elevators as shown in Fig.19..

B-Means of horizontal transport: in the buildings of the airports, roads expanded and extended hundreds of meters. Here the science turned to a moving mat to move the traveler at a safe speed to the place of his plane without any effort, as shown in Fig. 20.

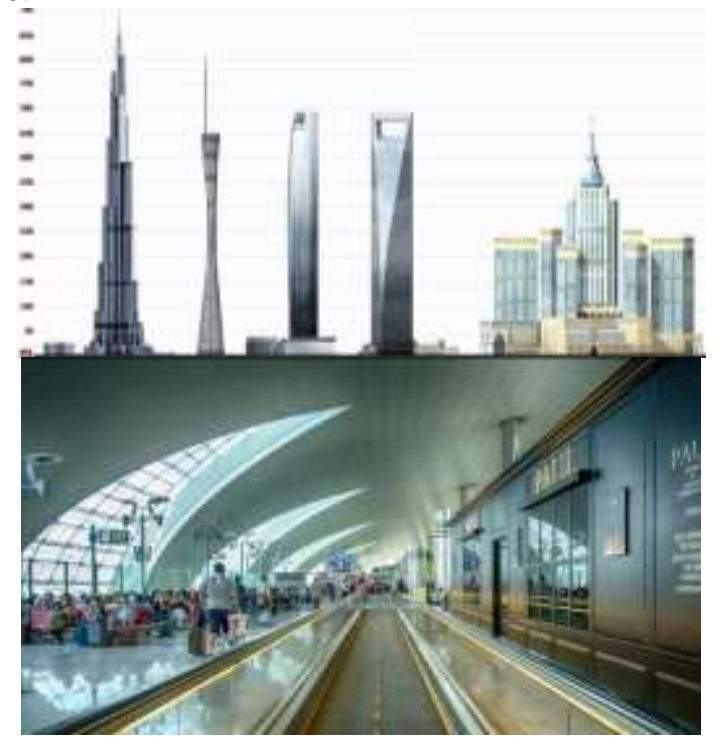

Fig. 19. Change in the form of architecture, most of which turned into skyscrapers that could not be set up without modern construction technology (Vertical Navigation)

Fig.20. Dubai International Airport and the use of moving mat to facilitate horizontal movement

\section{E. The use of computers in architectural design}

Within a few years, these devices have become very small and efficient, and the computer has become a key tool for anyone who works in architectural designs and construction calculations. Computer utility appeared in terms of: construction and design - the preparation of time tables - the implementation of the project - the preparation of tables of quantities to determine the economic feasibility of projects - and calculations of stress according to changing loads. 


\section{The Impact Of OIl Discovery On The Gulf States}

The discovery of oil has greatly affected the Gulf families and thus the Gulf society, which in turn became a modern industrial society, radically different from the traditional pastoral society.

\section{A. Economic aspect}

Until the early fifties the Gulf society was a Bedouin society. Then the oil wealth began to flow to the country and the Gulf States began to enter the stage of economic and industrial development that affected the Gulf families. Petroleum companies have become the way to rid them of the hard maritime professions such as diving. They switched to working in companies and formed a new labor class after the elimination of the divers and working class in simple professions. This resulted in population attraction and an intensive migration movement that led to a change in the urban, economic and demographic map of gulf society.

\section{B. Social aspect}

Before the discovery of oil, Gulf society lived away from any foreign communications. After the influx of oil, a new working class was formed, and foreign employees represented the majority, while indigenous people represent a minority compared to the foreign population. heterogeneity in population structure has led to major social problems

\section{The form of architecture Gulf after the discovery of oil}

A. Planning the modern Gulf city: The general structure of the modern Gulf city has been influenced by the scale generated by the fast-moving airstream. The streets and roads widened according to traffic densities, so that the traffic networks are the ones that determine the general shape of the city [9] This is apparent since the emergence of the first planned city in the Kingdom (Al Khobar 1947) [10] as shown in Fig. 21.

B. Urban space: The city was transformed from a closed city into a free city, from an Introvert architectural and urban style to an extrovert architectural style, with vertical growth trend.

C. The general nature of modern Gulf city: It is the image of the western city that prevailed. The city of the Gulf was transformed from an Arab city into a western city. It is noted that important construction works in the Gulf countries have been designed and implemented by European and American companies. Few of these understand the special environmental conditions of Gulf countries and respect the customs of their people. This appears in multi-story buildings that do not reflect a particular cultural identity, as shown in Fig. 22.

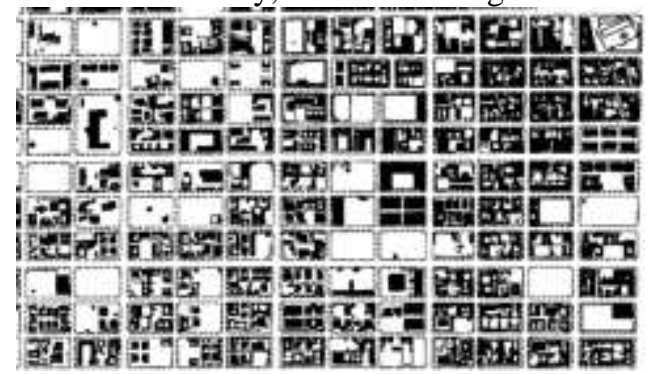

Fig. 21. news planning system. The first planned city in the Kingdom of Saudi Arabia (1947).

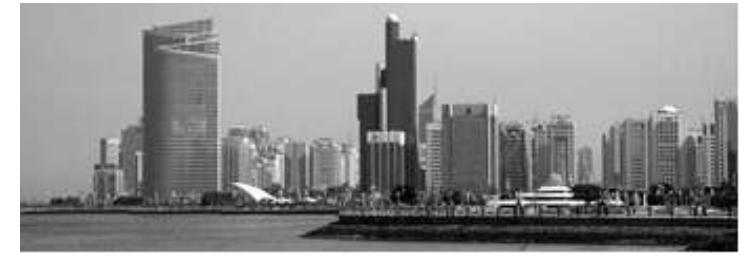

Fig.22. The waterfront of the Emirate of Abu Dhabi, modern architecture showing multi-story buildings that do not reflect a particular cultural identity.

D. Street properties in contemporary Gulf city: The height of buildings and disregard for the human scale. Street widths are compatible with the speedometer and automatic movement, resulting in a lack of social links between the neighborhood residents

E. Contemporary Gulf Residence: Certain changes occurred in the construction process, the first is that the core design concept of the house changed from introversion to extroversion, and thus used the finest types of finishing materials (marble, copper, aluminum and glass). The result of such new architectural forms is the loss of the distinctive character of the Arab architecture. Climatic conditions are not considered in the construction of houses for the availability of air conditioners. There is also a lack of attention to Windcatchers and Mashrabiya facilities for the availability of reflective glass and curtains made of fabric or metal. Therefore, most of the modern dwellings that were constructed lacked any character or specific architectural elements that distinguish each area from the other.

\section{ARChitectural AtTEMPtS To Blend The GulF HERITAGE WITH CONTEMPORARY ARCHITECTURE}

There have been few attempts to preserve the Gulf heritage by symbolizing the exterior the building, as shown in the following examples.

\section{A. Kuwait Towers}

For example, the towers of Kuwait were designed in 1975 to match the landmarks of Kuwait Heritage, the largest and main tower, which holds two balls signifies the "Evaporator - Al Mabkhar"( A bowl of coal and incense to produce a smell of sweet smoke), the second tower, which holds one ball signifies the "Sprayer - Al Marash"( A bottle of rose water in it, sprinkled on the people and their clothes), and the third and smallest tower signifies the " Almekhalh - Eye liner bottle". As shown in Fig. 23,24

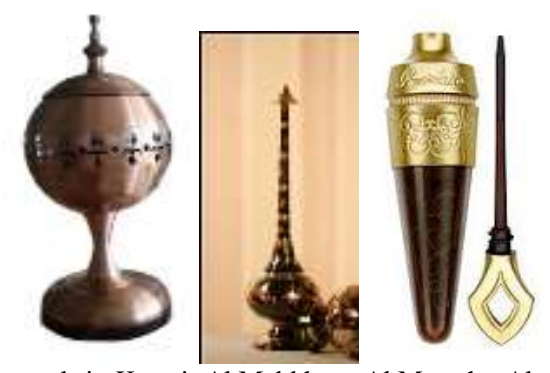

Fig.23. Heritage tools in Kuwait:Al Mabkhar - Al Marash - Almekhalh 


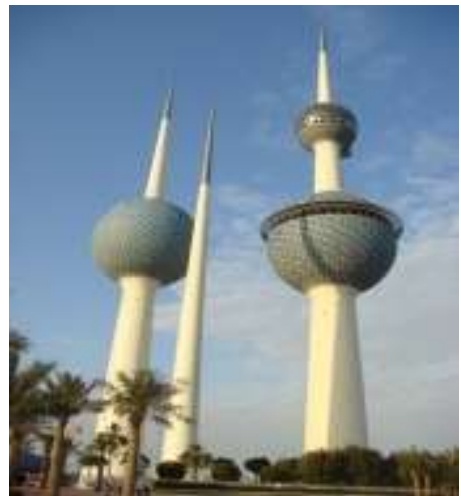

Fig. 24 Kuwait Towers design inspired by Kuwaiti heritage.

\section{B. Doha Tower in Qatar}

Designed by Pritzker Prize Winner Jean Nouvel, the tower is inspired by the Middle East architecture and cooling strategies, to be the first vertical garden, decorating the sky of Qatar. The layers of the screens, inspired by old mashrabiya that obscures the effect of intense sunlight, as shown in Fig.25.

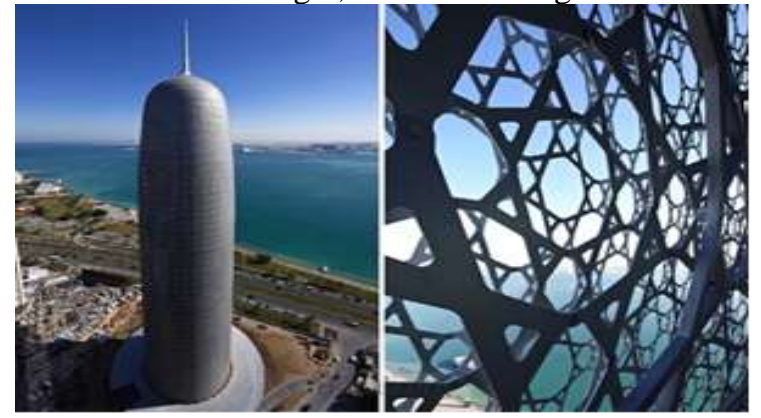

Fig.25 Doha Tower in Qatar: Using the idea of Mashrabiya in a modern way.

\section{CONCLUSION}

- Traditional architecture in the Arab region has provided spontaneous architectural solutions, without prior correlation with certain architectural or plastic considerations.

- Traditional architecture was a true reflection of the environmental conditions of the societies in which they originated in all their natural and social dimensions.

- The Gulf architecture continued to evolve in line with the environmental needs of the Gulf society and considered the natural and climatic conditions of the region. It clearly reflected the cultural characteristics and Arab traditions until the emergence of oil and the rise of the industrial revolution

- With the emergence of oil, the characteristics of the Gulf architecture differed, as did the construction of the Gulf family and the shape of the Gulf society.

- The contemporary Gulf buildings have become a continuation of the western architectural character, despite the differences in the characteristics of the environment and the composition of society.

- The architectural movement in the Arab countries is undergoing a real crisis, embodied in the disappearance of the personality and identity of Arab architecture. This architectural confusion is evident in the new Arab cities.

- We need to study the reasons that led to the disappearance of the Arab identity and work to resolve them and convert reasons to viable practical solutions to restore personality of Arab architecture.

\section{RECOMMENDATIONS}

\section{A. Recommendations at the level of governments of the Arab Countries}

- Providing the scientific disciplines which are required to develop the process of preserving the character of the Arab architecture, disciplines which are related to the economic and social dimensions at the national, regional and local levels.

- Involving qualified specialties; who have studied economic, social, geographical and architectural disciplines through their undergraduate and postgraduate studies, in the development process at the national, regional and local levels.

- Arab countries should organize conferences to sponsor remarkable contributors in the field of architecture and honor their intellectual works through awards. This shall highlight architectural excellence in their respective fields (social technical - organic - environmental) and support their contribution to promote contemporary Arab architectural.

- Architectural regulatory authorities should provide appropriate methods to stop infringements on archaeological areas by preventing demolition or alteration of the building or archaeological area without reference to the competent authorities.

- Establishing educational and training programs to prepare qualified cadres to deal with heritage in appropriate ways and methods.

- The governments should carry out upscale architectural projects to be taken as role models to follow by the small architectural sectors, to improve the Arab urban environment.

\section{B. Recommendations at the level of the competent authorities}

- There is need to work in constant communication among the architectural organizations in the Arab region and publishing their various programs of activities in the journal issued by the International Federation of Architects, through representatives of Arab architects in this union.

- Considering the selection of qualified persons in each area related to architecture who are able to participate in various activities carried out in non-Arab countries, and follow-up global architectural and planning activities, whether it is held conferences or organized exhibitions and lectures, to transfer these cultures and benefit from them in the architecture and urban planning of the Arab world.

- Activating an effective monetary movement in contemporary Arab architectural reality. This is a key input to correct the path of architectural movement, through the development of multiple standards of comprehensive architectural work. These standards are (utilitarian - aesthetic - constructional - environmental economic - cultural - social - political).

- Translation of Arabic architectural publications into other languages and translation of international publications into Arabic. Also seeking to make the new generation recognize their heritage and the heritage of world cultures. 
- Utilizing as much as possible the old Arabic architectural vocabulary and developing it in contemporary and future buildings.

- Preservation of the ancient Arab heritage of clothing, furniture, doors, windows and architectural vocabulary, and manufacturing them in factories and workshops specialized in producing and developing these items, in order to preserve the Arab heritage in a sophisticated manner.

\section{Recommendations at the academic level}

- Development of architectural education (scientific content) to increase the architectural awareness of the student and the future engineer. It is a core learning outcome to identify the importance of traditional architectural solutions and the Arab environment, to preserve the basic values and distinctive heritage character, and make it one of the most important approaches to the process of architectural design. This should be accomplished without neglecting the intellectual and technological characteristics of the 21 st century, we are not to lose touch with our past nor with the present.

- Determining several architectural courses in different educational stages that contain appropriate scientific content about the preservation of the Arab environment and its basic values and distinctive character, while providing the possibility of teamwork integration during these courses so that each student knows his role in this system in practical reality.

- Dealing with the problem of urban planning education during the undergraduate and postgraduate levels through the integration of economic and social planning with its spatial dimension, expressed in Urban design, whether at the national, regional or local level.

- Teaching students of architecture and history the processes of restoration and re-employment of buildings. Students should learn scientific assets of archaeological architecture through academic education, scientific research and community service.

\section{REFERENCES}

[1] M. Ibrahim, Arab Architecture, Architecture and Urbanization in the Arab World, Beirut : Dar Rateb Press, 1976
[2] A.B. Ibrahim , Cultural heritage in the contemporary Arab city, Cairo: Urban and Architecture studies Center Press, 1968.

[3] M. B. El-Kholly, Climate Impact and Arab Architecture, Cairo : Dar Elmaaref Press, 1977.

[4] A. Nanji., The Aga Khan Program for Islamic Architecture, In Building for Tomorrow, London: Academy Group Ltd., 1994.

[5] Y. Elsheshtawy, The Evolving Arab city, traditional, modern, urban development,2nd ed, oxford, 2011.

[6] F. Ragette, Traditional Domestic Architecture of Arab Region, Shagra : American university Ltd., 2003

[7] T. Abdel Gawad, History of Architecture and Islamic Art, Cairo : The Anglo Egyptian library Press, 2010.

[8] F. Wiedmann, A.M. Salama and H. Ibrahim . (March 2016). The role of Mega Project in Redefining Housing Development in Gulf Cities. [Online]. $41(2) . \quad$ pp. 56-63. Available: https://strathprints.strath.ac.uk/55760/8/The_Role_of_Mega_Projects_i n_Redefining_Housing_Development_Gulf_Cities_Wiedmann_Salama _Ibrahim.pdf



Dr. Salma Dwidar Associate professor in Architectural Department, currently works at Department of Architecture Engineering, Faculty of Engineering, Prince Sultan University, KSA. Before, she worked as an Associate professor of College of Fine arts, Alexandria Univ., Egypt. She has served as Lecturer in Department of Architectural Engineering, faculty of Engineering, Mansoura University, Egypt. Her area of research is in Architectural Design and Theory and History of Architecture; she has published many papers in refereed International Conferences and Architectural Journals. She is invited to be guest speaker in many national and international conferences. She is supervised and designed many Architectural Projects, Urban plan Projects. Dr. Salma holds PhD. (philosophy degree in Architecture) from Architectural department, Faculty of fine arts, Alexandria University, Egypt.

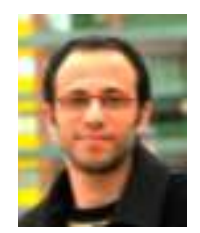

Dr. Akram Zayan Assistant professor in Architectural Department currently works at Department of Architecture, Faculty of Fine Arts, Alexandria University, Egypt. He works as Lecturer deputized in faculty of Engineering, Arab Academy for Science and Technology. His area of research is in Architectural Design and Bio-mimicry and History of Architecture; He has published many papers in refereed International Conferences. He is supervised and designed many Architectural Projects, Urban plan Projects. Dr. Akram Zayan holds PhD. (philosophy degree in Architecture) from Architectural department, Faculty of fine arts, Alexandria University, Egypt 